\title{
Los inicios en prensa de Francisco Umbral: las colaboraciones en La Estafeta Literaria
}

\author{
Margarita GARBISU BUESA \\ Universidad a Distancia de Madrid, UDIMA \\ margarita.garbisu@udima.es
}

\begin{abstract}
RESUMEN
El presente artículo pretende sacar a la luz las colaboraciones que Francisco Umbral firmó durante la década de los sesenta en la revista La Estafeta Literaria, uno de los medios de Madrid en los que empezó su trayectoria periodística. Las colaboraciones de La Estafeta suman casi dos centenares y abarcan todos los géneros: la crítica, el artículo, la crónica, la entrevista o la creación. El objetivo que se persigue es, además de rescatarlas del olvido, situarlas en el contexto de la trayectoria del autor y en de la propia publicación. Para completar la información se incluirá un anexo con un detallado elenco de todos los títulos escritos por Umbral en la revista.
\end{abstract}

Palabras clave: Francisco Umbral, La Estafeta Literaria, periodismo literario, siglo XX, años 60 , revistas culturales.

\begin{abstract}
This article brings to light the contributions of Francisco Umbral during the sixties in $L a$ Estafeta Literaria, one of the reviews published in Madrid, where his journalistic trajectory started. He penned nearly two hundred contributions: articles, interviews, chronicles and works of fiction. The aim of this paper is to recover them and to place them in the context of the review itself and of the author's trajectory. To complete this information an exhaustive list of all the texts written by Umbral for the Estafeta is provided in the annex.
\end{abstract}

Key words: Francisco Umbral, La Estafeta Literaria, literary journalism, XX Century, sixties, cultural reviews.

La trayectoria de Francisco Umbral se enmarca entre 1957 y 2007, el año de su fallecimiento. Diez lustros, por tanto, de creación que han dejado a las letras españolas miles de artículos en prensa y decenas de volúmenes de narrativa, ensayo o memorias. Ante tan prolífica obra es inevitable pensar que aún queda mucho por contar, investigar y rescatar del legado del escritor; rescatar un bloque de ese legado es precisamente el punto de partida del presente trabajo, en concreto, sacar del 
olvido un interesante parte de su obra periodística: la de sus inicios, la de un joven Umbral recién llegado a Madrid a principios de los sesenta.

Umbral se inicia como escritor con colaboraciones esporádicas que publica desde 1957 en el periódico vallisoletano El Norte de Castilla ${ }^{1}$; el vínculo directo con este medio se mantiene hasta 1969, si bien el autor vive en Madrid desde 1961. No es hasta el mismo 1969 cuando Umbral cuenta con un espacio diario en prensa al pasar a fomar parte de la nómina de Colpisa, agencia de noticias que envía su escrito a diversos medios regionales; el personal sello de Umbral empieza entonces a darse a conocer por toda España. En 1976 llega el salto definitivo en su carrera cuando entra en el recién nacido diario El Pais; su voz sigue expandiéndose, fortaleciéndose y ganando adeptos y detractores durante la más de una década que permanece en el medio. En 1988 es contratado por el Diario 16 y un año después por el también recién nacido El Mundo. En El Mundo escribe su última columna, en la contraportada, en la sección «Los placeres y los días».

El espacio de la trayectoria de Umbral entre 1969 y 2007 ha sido ampliamente tratado, desde perspectivas diversas, en estudios y artículos académicos ${ }^{2}$. Sin embargo, la producción que abarca los años 1957-1969 no ha corrido la misma suerte y ha sido bastante menos analizada. Juan Gracia Armendáriz recogió una parte de esta producción en su tesis doctoral El artículo diario de Francisco Umbral (1957-1988): análisis y documentación, un exhaustivo trabajo sobre la obra periodística del autor desde sus inicios hasta el momento en que abandona el diario El País ${ }^{3}$. Dentro del periodo sugerido (1957-1969), Armendáriz indexó los escritos

\footnotetext{
${ }^{1}$ Sin embargo, García Armendáriz fecha el primer texto de Umbral en prensa en 1955; se trata de un «artículo titulado "La mañana", que apareció en las páginas de la revista $A R C O$, una publicación del distrito universitario de Oviedo perteneciente a la Facultad de Veterinaria» (Gracia Armendáriz [2003], p. 189). No obstante, durante el proceso de corrección de este texto, se ha publicado un artículo que retrasa la primera publicación en prensa del autor, en el diario Proa de León, a abril de 1954 (Véase: Fernández-Sande, Martínez Rico [2014], pp. 357-376).

${ }^{2}$ Véanse, entre otros muchos, los trabajos de Juan Cantavella («Columnas para sostener el mundo») o Bernardo Gómez Calderón («Sobre la preceptiva articulista de Francisco Umbral: el magisterio de César González Ruano»), incluidos en el volumen coordinado por Carlos X. Ardavín con título Francisco Umbral. Ensayos críticos en torno a su obra (Gijón, Llibros del Pexe, 2003); o «La transición democrática en el periodismo político de Francisco Umbral», ensayo firmado asimismo por Carlos X. Ardavín (Arbor, 642 [1999], pp. 179185); o los trabajos al respecto, publicados en el monográfico que la revista Intramuros dedicó a Umbral en el otoño/invierno de 2010-2011: B.J. Gómez Calderón: «Urgencia y lirismo: el Umbral columnista», Intramuros, 32 (2010-11), pp. 30-31; S. Robles: «Las personas del verbo umbraliano en las columnas poético- periodísticas», Intramuros, 32 (2010-11), pp. 34-35.

${ }^{3}$ Esta tesis doctoral fue leída en 1995 en la Universidad Complutense de Madrid, y constituyó la primera escrita en España sobre Francisco Umbral. En 2002 la propia
} 
de El Norte, los del diario Proa y los del Diario de León, no así los de otros medios en los que Umbral también trabajó durante esos años. Porque ya se ha dicho que en 1961 el escritor se traslada a Madrid y allí, en la capital, colabora con otras revistas; una de ellas es La Estafeta Literaria, publicación nacida en 1944 que, con temporadas de silencio, permanece viva hasta 2001 a lo largo de siete etapas. Umbral publica en ella con asiduidad en sus etapas tercera, cuarta y quinta, entre 1961 y 1970, es decir, en el espacio temporal referido.

Es fácil, por tanto, deducir que el fin específico de este trabajo se centra en los textos periodísticos que Francisco Umbral escribe en La Estafeta durante estos años; suman casi dos centenares y abarcan todos los géneros, desde la crónica a la entrevista, desde la crítica a la noticia. Son bastante desconocidos y, sin embargo, en ellos se percibe al Umbral posterior, con su frescura, su ingenio, su ironía y su agudeza en el lenguaje.

No se persigue entrar en el análisis estilístico o de contenido de estos escritos; se persigue simplemente el paso previo: como se ha sugerido, rescatarlos del olvido. Por ello, metodológicamente, la sencillez en el planteamiento va a marcar nuestra pauta. El trabajo se va a estructurar en dos partes bien diferenciadas, una de contextualización y otra de documentación; o dicho de otra manera: la primera parte -el grueso del escrito o el artículo en sí- va a tratar de situar los textos de $L a$ Estafeta Literaria en el tiempo, en la circunstancia vital y profesional del escritor, así como en el contexto de la propia publicación; evidentemente no se irá describiendo individualmente cada aportación -sería esta tarea imposible dado el volumen de escritos- sino que se explicarán las líneas generales de la colaboración umbraliana en cada etapa de la revista. Todo ello va a encontrar su apoyo y complemento en la segunda parte del trabajo, un detallado anexo con las referencias de todos los títulos firmados por el escritor en La Estafeta, clasificados por etapas.

De este modo este artículo, básicamente descriptivo, quiere convertirse en una herramienta para futuras investigaciones que nazcan a partir de estos textos; textos ignotos y necesitados de un profundo estudio que dé a conocer mejor el periodismo del primer Umbral, el del periodo 1957-1969, los años que constituyen -el propio Gracia Armendariz así lo afirmó- «la etapa menos conocida de la obra periodística del autor» ${ }^{4}$.

\section{Los inicios periodísticos de Francisco Umbral: la llegada a Madrid}

Como se ha adelantado Francisco Umbral comienza su verdadera carrera periodística en Valladolid en El Norte de Castilla, en concreto, en el suplemento

universidad la publicó: J. Gracia Armendáriz: El artículo diario de Francisco Umbral (1957-1988): análisis y documentación, Madrid, Universidad Complutense de Madrid, 2002 [ http://eprints.ucm.es/tesis/19911996/S/3/S3012301.pdf].

${ }^{4}$ J. Gracia Armendariz (2002), p. I. 
«Las Artes y las Letras» de este periódico. Anna Caballé, en la biografía que dedica al escritor, fecha su primera colaboración el 21 de marzo de 1957: un artículo de temática literaria (algo habitual en su inicios), que llevó por título «Tres actitudes de la lírica española contemporánea» y por firma, la de Francisco Pé́ez, su verdadero nombre 5 .

Como también se ha adelantado, el vínculo directo con El Norte durará doce años, hasta 1969, no así la estancia en la ciudad que lo aloja. En abril de 1958 Umbral se traslada a León, para cubrir un puesto vacante como administrativo en la emisora radiofónica La Voz de León; allí llega con una carta de recomendación de Miguel Delibes, quien desde ese mismo año ha pasado de subdirector a director de El Norte. Umbral gana la plaza en la radio y en seguida supera las tareas inicialmente encomendadas, para adentrarse en las de guion y realización. Es entonces cuando Umbral empieza a llamarse Umbral ${ }^{6}$, y cuando este nombre Umbral, Francisco Umbral- comienza a darse a conocer entre los leoneses, pues sus guiones radiofónicos van cosechando éxito y oyentes.

A ello hay que añadir las colaboraciones en prensa -en el diario Proa y el Diario de León ${ }^{7}$ y la vida cultural leonesa, que el propio autor se encargó de avivar con la organización de diversas actividades en el Círculo Medina de la Sección Femenina de la Falange. Como consecuencia de una de estas actividades, Umbral viaja a finales de 1960 a Madrid, invitado por José Hierro, quien le propone una lectura en el Ateneo para el 16 de diciembre de ese año ${ }^{8}$. Una vez en la capital, comprende que, si quiere convertirse en escritor, es en Madrid donde debe estar, y no en León.

${ }_{6}^{5}$ A. Caballé (2004), p. 135.

${ }^{6}$ Caballé explica que los periódicos leoneses Diario de León, Proa y La Hora de León publicaban en sus páginas la programación de la emisora y que «un jueves, 2 de octubre de 1958, como responsable de una sección que venía emitiéndose a media noche titulada Buenas noches» aparece por primera vez el nombre de Francisco Umbral (A. Caballé [2004], p. 140).

${ }_{7}$ Como explica Gracia Armendáriz, «en el primero de ellos (...) Umbral comenzó a colaborar en la sección de información universitaria»; en el segundo, publicaba de cuando en cuando crítica literaria hasta que en enero de 1961 es contratado como articulista diario; sacó la serie de veintiún textos titulada «La ciudad y los días», lo que supuso «la primera incursión de Francisco Umbral en el artículo diario» (Gracia Armendáriz [2003], p. 195).

${ }^{8}$ La invitación de Hierro fue en respuesta una invitación previa de Umbral al poeta para que realizara una lectura lírica en el círculo; había tenido lugar en el mes de enero de 1960 (Caballé [2004], pp. 149-150).

Esta primera visita de Umbral a Madrid da inicio a La noche que llegué al Café Gijón, que dice: «La primera noche que entré en el Café Gijón puede que fuese una noche de sábado. Había humo, tertulias, un nudo de gente en pie, entre la barra y las mesas, que no podía moverse en ninguna dirección, y algunas caras vagamente conocidas, famosas, populares, a las que en aquel momento no supe poner nombre. Podían ser viejas actrices, podían ser prestigiosos homosexuales, podían ser cualquier cosa. Yo había llegado a Madrid para dar 
Umbral sospecha entonces que no le queda mucho tiempo en la ciudad castellana $\mathrm{y}$, en efecto, un altercado con la encorsetada sociedad leonesa se convierte en el acicate que le lleva a abandonarla ${ }^{9}$. A principios de febrero de 1961 pone finalmente rumbo a la capital.

Llega a Madrid con muchas ganas, nuevas cartas de recomendación y algo de dinero. Su principal salario, el percibido por los artículos de El Norte de Castilla, no es suficiente para vivir con holgura por lo que tiene que buscar otras colaboraciones como medio de ingreso pecuniario y también intelectual. El escritor vaga por la ciudad: vuelve a los lugares que en su breve visita anterior le habían seducido - al Ateneo, al Gijón-, indaga otros nuevos y trata de contactar con personas diversas a la caza de textos que colocar:

Por las mañanas salía con mis cartas de recomendación, con mi cartera, con mis cuatro cosas, a visitar oficinas, redacciones, sitios donde me pudieran dar trabajo (...).

Yo era el que se levantaba el último en las pensiones y salía a la calle sin prisa, sin nada que hacer, cosa que les tranquilizaba muy poco a las patronas, yo era el que cogía metros, autobuses, trolebuses, tranvías, y miraba mucho las direcciones, para no confundirme, y visitaba los Ministerios, los periódicos, las redacciones de escondidas revistas sin tirada, los bares traseros de la Gran Vía, los sitios donde me decían que podía haber un trabajo, algo que redactar, una publicidad, un anuncio, un artículo, un guion, un texto, una traducción, incluso un spot de televisión ${ }^{10}$.

Las idas y las venidas, y las cartas de recomendación acaban dando su fruto y, entre las últimas, especialmente la que Delibes dirige a José García Nieto, director de Poesía Española y redactor jefe de Mundo Hispánico. García Nieto queda deslumbrado «por la facilidad de pluma y el talento de aquel joven prometedor y cargado de confianza en sí mismo», explica Caballé ${ }^{11}$, y en seguida le contrata para ambas publicaciones. Pero no son las únicas ya que a ellas hay que añadir Punta Europa, dirigida por Vicente Marrero, Vida Mundial, a cargo de Manuel Cerezales y, como ya sabemos, La Estafeta Literaria, al mando entonces de Rafael Morales.

una lectura de cuentos en el aula pequeña del Ateneo, traído por José Hierro, y encontré, no sé cómo, un hueco en uno de los sofás del café» (F. Umbral [2008], p. 629).

${ }^{9}$ Umbral protagonizó un escándalo a raíz de un cineforum que él mismo dirigió el 8 de enero de 1961en el Círculo Medina sobre la película Orfeo de Jean Cocteau; Ana Caballé relata detenidamente el episodio del cinefórum y el abandono de León, en una parte del capítulo de la biografía de Umbral titulado «Un escándalo provinciano» (A. Caballé [2004], pp. 151-167).

${ }^{10}$ F. Umbral (2008), p. 638.

${ }^{11}$ A. Caballé (2004), p. 180. 
A juzgar por lo que el propio Umbral explica, la vía de entrada en la publicación fueron dos de sus redactores, José Julio Perlado y Manuel García Viñó:

José Julio Perlado, de curioso parecido físico con Fraga Iribarne (solo parecido físico), me echó una mano para que metiese artículos en La Estafeta, pues los artículos había que meterlos en algún sitio. Manuel García Viñó, sevillano, poeta, novelista, crítico de arte, casado con la admirable pintora Pepi Sánchez, también andaluza, y que vivía en el barrio de la Concepción, abrumado de libros y de hijos, también me pedía cosas para la revista, e incluso el propio Rafael Morales ${ }^{12}$.

Lo cierto es que el interés del autor por esta revista venía de atrás ya que en el número 183 del 15 de diciembre de 1959, cuando Umbral vivía aún en León, aparece un artículo con su firma titulado «Eugenio D'Ors, maestro imposible». Este va a ser el primer texto de Umbral en La Estafeta; veintiún años después -en abril de 1980- se fecha el último, un fragmento de la novela Los helechos arborescentes, que ve la luz ese $a \tilde{n}^{13}{ }^{13}$. Ahora bien, ninguna de estas dos aportaciones resultan significativas del vínculo del autor con la revista, ya que ambas se salen del espacio temporal en el que se enmarca la colaboración: la primera proviene de un joven y desconocido autor que todavía ni siquiera sueña con Madrid; la última, por el contrario, de un escritor consagrado que goza de prestigio y fama en toda España, y hace ya tiempo que ha abandonado la revista.

En realidad se puede afirmar que Francisco Umbral escribió con asiduidad en La Estafeta Literaria -mayor o menor dependiendo del momento- entre finales de 1961 y finales de 1970, es decir y como se ha adelantado, en las tres épocas intermedias de la vida de la publicación: la tercera y, sobre todo, la cuarta y la quinta. Pero situémonos, porque La Estafeta Literaria vivió a lo largo de sesenta años, durante siete épocas discontinuas; y si Umbral comenzó su andadura en su tercera etapa, quiere decir que existieron dos previas.

\section{La Estafeta Literaria: las colaboraciones de Francisco Umbral en las diversas etapas}

La Estafeta Literaria había nacido en plena posguerra, en concreto, el 5 de marzo de 1944, con periodicidad quincenal y bajo la dirección de Juan Aparicio. La intención del director fue continuar la línea marcada por La Gaceta Literaria (19271932) de Ernesto Giménez Caballero, esto es, dar vida a una revista literaria aunque

\footnotetext{
${ }^{12}$ F. Umbral (2008), p. 653.

${ }^{13}$ Con el fin de no engrosar el artículo con un aparato de notas que se extendería demasiado, remitimos al lector al anexo final para conocer las referencias concretas de los textos citados. Solo se incluirán la referencia completas a pie de página cuando sea estrictamente necesario.
} 
no ceñida exclusivamente a la las letras, que recogiera información, creación y crítica cultual de dentro y fuera de España; esta era la teoría, la realidad fue que el espíritu internacional de su predecesora se vio sustituido por un tono españolista, acorde con la circunstancia histórica que el país estaba viviendo.

Esta primera época se prolongó hasta enero de 1946 con el ejemplar número 40. Tras un paréntesis de una década, el 29 de abril de 1956 nació la segunda fase de $L a$ Estafeta, con periodicidad semanal; en un primer momento fue dirigida por el propio Aparicio, quien cedió después el testigo a Luis Jiménez Sutil. La súbita muerte del director provocó que esta época se viera interrumpida el 6 de julio de 1957, tan solo un año y tres meses después de su nacimiento. Sobra decir que la línea de la revista no había variado en exceso desde sus inicios.

El verdadero cambio de La Estafeta se produce precisamente con la tercera época, que nace el 16 de noviembre de 1957, con la vuelta a la periodicidad quincenal (a partir de 1959) y la dirección de Rafael Morales; se extiende hasta septiembre de 1962. El mes siguiente, ve la luz la cuarta época, con la misma periodicidad y la dirección de Luis Ponce de León; permanece viva algo más de cinco años y medio, hasta febrero de 1968, momento en el que Ponce de León cede el testigo a Ramón Solís. La quinta fase empieza, por tanto, el 9 de marzo de 1968, y se prolonga durante diez años, hasta octubre de 1978.

La vida de la revista es larga y aún le quedan dos etapas más, ambas nacidas ya en democracia: la sexta o Nueva Estafeta, que vive casi un lustro (entre diciembre de 1978 y junio de 1983), a cargo de Luis Rosales, y finalmente una exigua séptima época que nace catorce años después, en 1997, bajo la dirección de Manuel Ríos Ruiz y su nombre de siempre; La Estafeta Literaria muere, parece que definitivamente, en $2001^{14}$.

Al hablar de la historia de La Estafeta se ha considerado que las tres etapas intermedias (la tercera, cuarta y quinta) configuran la edad de oro de la publicación; precisamente -ya lo sabemos- las de colaboración umbraliana.

\subsection{Las contribuciones de Umbral en la tercera época (noviembre 1957- septiembre 1962: números 104-249)}

En La noche que llegué al Café Gijón Umbral dedica unas palabras a La Estafeta Literaria de esta tercera época y a su entonces director, Rafael Morales; dice así:

La Estafeta Literaria, que dependía del Ateneo, la dirigía Rafael Morales, poeta grande y riente, con una bondad errante y perdida por su rostro largo de ojos enormes -agrandados por las gafas- y risa un poco exagerada de dientes. Rafael

\footnotetext{
${ }^{14}$ Para conocer las diferentes etapas y la vida de la publicación véase: M. Garbisu Buesa; M. Iglesias Berzal: Índices de La Estafeta Literaria (1944-2001). Contenidos literarios de la revista. Madrid, Fragua, 2004.
} 
Morales era talaverano, católico y apacible, y se había hecho famoso -haciendo famosa al mismo tiempo la colección Adonais- con su libro de los Poemas del toro, que estaba entre Lope y Miguel Hernández, pero con acento muy propio y giros muy personales ${ }^{15}$.

Como decíamos, Morales propicia el gran cambio de La Estafeta, pues modifica su estética y su contenido. Si en las etapas anteriores La Estafeta se asemejaba en formato a un periódico con color (cuando salió se ganó el apodo de «TBO de la letras»), a partir de ahora pasa a convertirse en una revista de menor tamaño, en blanco y negro, y con aspecto digamos que más académico. Asimismo el espíritu de la publicación da un importante giro con la inclusión de nuevas secciones, nuevas firmas y más cosmopolitismo (lo que Aparacio había intentado sin lograrlo). En el editorial que da la bienvenida a la nueva época, se exponen los objetivos que desde ahora la revista persigue: primero, no limitarse exclusivamente a lo literario y dar cabida a otras disciplinas artísticas; segundo, ampliar seriamente la mirada a otros mundos y culturas; tercero, servir de trampolín a jóvenes creadores, sin olvidarse de los consagrados; y cuarto, dar cabida a aspectos variados de las letras desde «la información, la crítica, el ensayo breve, el artículo, el cuento, la poesía, la crónica, el reportaje o la entrevista» ${ }^{16}$.

Los dos últimos aspectos mencionados -que se convierten desde este momento en una constante en la vida de la revista- se ajustan perfectamente a la trayectoria de Francisco Umbral en su aterrizaje en Madrid: Umbral es un joven creador que, en 1961, con tal de escribir está dispuesto a sacar cualquier cosa, sea en el género periodístico que sea; así se comprueba, más que en esta etapa, en la sucesiva, porque en la tercera época estafetiana Umbral tan solo publica doce textos, incluyendo el enviado en 1959 desde León.

La relación real de Umbral con La Estafeta, ya asentado el autor en la capital, comienza en 1 de noviembre de 1961 cuando, en el número 228, sale «Hacia una nueva épica»; después tienen e pasar tres meses y medio para hallar el siguiente escrito con su firma («Asalto a la Puerta del Sol», en el número 235, de febrero de 1962) y después dos meses más y dos más; en definitiva, que no es hasta junio de 1962 y ya en el declive de esta etapa, cuando las colaboraciones de Umbral se pueden leer con continuidad en los ejemplares -aún no en todos- de la publicación.

A excepción de cuatro, todas las colaboraciones de esta época son artículos literarios en los que sobrevuela una temática común: el rechazo a la literatura social y la defensa del autor novel, tema este último especialmente susceptible para él por

\footnotetext{
${ }^{15}$ F. Umbral (2008), p. 653.

${ }^{16}$ «De cara a la esperanza», La Estafeta Literaria, 104 (16-XI-1957), p. 1.
}

En adelante, para las referencias extraídas de la revista se referirá el nombre La Estafeta Literaria con las siglas $L E L$. 
su propia condición ${ }^{17}$. Comienza también entonces su incursión en la literatura extranjera - una constante en su futura trayectoria periodística- en artículos como «Rilke en España».

La excepción mencionada la constituyen cuatro reseñas bibliográficas, incluidas en la sección Libros: dos de narrativa (sobre obras de Máximo Regidor y José Acosta Montoro) y dos de ensayo (sobre obras de Heinz Häfner y Lorenz Jaeger). Con ellas nos encontramos ante los primeros textos de crítica literaria de Umbral para la revista; en este sentido, Gracia Armendáriz afirma que La Estafeta es, junto con Vida Mundial y Poesía Española, una de «las publicaciones especializadas donde Umbral consigue dar a la luz un mayor número de textos de creación y de crítica de poesía» ${ }^{18}$. Veremos después si así se cumple.

Esta tercera época se cierra con doblete del escritor en la última entrega: «Asedio a la juventud» y «Leopoldo Panero y la generación del 36», dos artículos que anuncian una fructífera colaboración en etapas posteriores.

\subsection{Las contribuciones de Umbral en la cuarta época (octubre 1962- febrero 1968: números 250-390)}

También en La noche que llegué al café Gijón, Umbral escribe lo siguiente:

De la noche a la mañana echaron a un ministro y entró otro, Fraga Iribarne, y todo aquel paisaje humano del Ateneo se renovó. De director de La Estafeta pusieron a Luis Ponce de León, que llegó a la cacharrería con su masculinismo cordial, reticente y a veces agresivo, y en seguida me dijo:

- Qué bien escribes, chaval.

Luis Ponce de León tenía algo de púgil cansado de derechas. Practicaba un vitalismo perezoso de hombre teóricamente de acción, y escribía con una agresividad dosificada que le creaba muchos enemigos. Yo no estaba de acuerdo con ninguna de sus ideas, ni él con las mías (si es que tenía ideas, por entonces), pero le interesaba mi estilo, y a mí me interesaba publicar donde fuese y como fuese, sobre todo teniendo en cuenta que los escasísimos reductos de la resistencia intelectual se cerraban misteriosamente al recién llegado ${ }^{19}$.

En efecto, la cuarta época de La Estafeta ve la luz con la entrega número 250 en octubre de 1962, el mismo año en que Manuel Fraga Iribarne se pone al frente del Ministerio de Información y Turismo; la labor del ministro tendrá su mejor muestra en la promulgación de la famosa ley Fraga, esto es, de la nueva Ley de Prensa de 1966 que suplantaba a las disposiciones anteriores de 1938 y significaba la

${ }^{17}$ El rechazo a la literatura social se aprecia en el ya citado «Hacia una nueva épica», y la reivindicación del autor novel, en «Asalto a la Puerta del sol», de los número 228 y 235, de noviembre de 1961 y febrero de 1962, respectivamente.

18 J. Gracia Armendáriz (2002), p. 43.

${ }^{19}$ F. Umbral (2008), p. 654. 
distensión de la férrea censura dominante. Un ambiente intelectual, por lo tanto, más relajado, que ayuda a Luis Ponce de León a asentar en La Estafeta la línea marcada por su predecesor, incluyendo un mayor número de páginas, de colaboradores y de puntos de vista.

Esta cuarta época vive algo más de cinco años y medio, exactamente hasta el 24 de febrero de 1968, y en ella la presencia de Umbral es constante. Los primeros textos con su firma salen en el número inicial: un artículo con el título «Gerardo Diego en el café» y una reseña sobre García Yagüe; el último, en enero de 1968, en casi el ocaso de la etapa, con el epígrafe «Sexo y muerte en García Lorca»; entre medias, ciento cinco textos más que, en comparación con los doce de la fase de Morales, suponen un aumento considerable.

No es descabellado, por consiguiente, afirmar que en este momento Umbral asienta su condición de colaborador asiduo de la revista; sus contribuciones siguen, además, una trayectoria, una evolución que va de la euforia al colapso, del crecimiento progresivo en el inicio de la etapa al parón repentino -consecuencia de las circunstancias- a partir de 1966.

\subsubsection{Entre 1962 y 1965: El apogeo}

Como se ha adelantado, desde el momento en que se abre esta época, en octubre de 1962, ahí está Umbral con dos colaboraciones: el citado artículo sobre Gerardo Diego, un texto cargado de nostalgia que rememora las conferencias pronunciadas por el poeta en provincias, y la crítica sobre García Yagüe, también referida. Dos artículos más completan ese año ${ }^{20}$.

Comienza así un fructífero 1963, variado - muy variado- en sus tres primeros meses: Umbral estrena el año con una encuesta sobre el «Horóscopo literario para 1963», continúa con tres escritos sobre Cela, Gómez de la Serna y el café Gijón, para dos secciones diversas -Correspondencias y Estafeta de las provincias-, y finaliza el trimestre con una entrevista a varios intelectuales sobre «la polémica del jaz (sic)». Es en este periodo cuando hallamos por primera vez un texto de ficción con su firma, en concreto, un relato titulado «Mapamundi», que se incluye en la sección Literatura viajera del número 257, del 19 de enero; esta faceta creadora verá meses después su continuidad en «El guateque», un nuevo relato publicado en el número 272-273 del 17 de agosto.

El del 17 de agosto es un ejemplar doble por tratarse de un monográfico dedicado al mapa literario de la Tierra de Campos; en él encontramos de nuevo la pluma de Umbral en un extenso artículo titulado «La escuela periodística del Norte

\footnotetext{
20 «Oficios y beneficios del escritor», y «Libros españoles para los niños del mundo» (sección Los libros), en los números 251 y 254, de octubre y diciembre de 1962, respectivamente.
} 
de Castilla», diario para el que sabemos que colaboraba y al que le unía un fuerte vínculo; otro doblete del autor, por tanto, en su trayectoria estafetiana.

Antes y después de este ejemplar, tres nuevos artículos con temática relacionada llevan su firma: se trata de «Eutrapelia intencionada sobre el compromiso del escritor. Derechos del escritor y derechos de la mujer», «Literatura y opresión» y «Escribas y fariseos», publicados en los número 266, 268 y 275, de mayo, junio y septiembre de 1963 respectivamente. La situación del escritor y de la literatura en España es el argumento que los vincula y que, además, los relaciona con los escritos de temática literaria de la etapa anterior: una interesante muestra, por consiguiente, del pensamiento crítico umbraliano.

Pero un apunte añadido aporta un especial valor a estos tres artículos: el último de ellos viene precedido por una nota sin firma alguna (posiblemente escrita por el director) que dice así:

De rato en rato, Francisco Umbral deja sobre la mesa del Director de La Estafeta un artículo, con igual ademán que dejaría caer una hoja mustia o una chaqueta fatigada.

Los últimos parecen hojas de la misma rama o chaquetas del mismo vagabundo. Véanlos ustedes en nuestros números 266 y $268^{21}$.

Además de apreciarse en estas palabras la relación temática entre los tres textos, llama la atención el "de rato en rato» que lo encabeza, indicativo de la aún esporádica presencia de Umbral en el medio; estamos en septiembre de 1963, y esta presencia esporádica pronto va a convertirse en continua.

Porque entre noviembre de ese año y junio de 1964 Umbral firma con cada vez mayor frecuencia reseñas bibliográficas para la sección Los libros, reseñas fundamentalmente de narrativa y no tanto de poesía ${ }^{22}$. Pero es en el número 293, del 6 de junio de 1964, cuando se produce el vínculo definitivo entre el escritor y la publicación, a raíz de una sección fija titulada $A$ la llana cultura que nace con esa entrega. Según reza el comentario que la presenta, el objetivo que persigue es acercar la revista a todo tipo de público -algo a menudo difícil para un revista de carácter literario y cultural-, erradicando los elitismos de la belleza y demostrando que la cultura se puede hallar también en la calle, en el día a día, en «el fútbol, el cine barato, la canción ligera o los rudimentos técnicos que decoran a la personalidad de cualquier hombre sencillo». ¿El elegido para sacarla adelante?:

${ }^{21}$ «Escribas y fariseos» (presentación), LEL, 275 (28-IX-1963), p. 5.

${ }^{22}$ La única reseña poética de estos meses es «Poesía. Juan Ramón, inédito», LEL, 279 (23XI-1963), p. 19. Sin embargo, publica reseñas de narrativa de Camilo José Cela, Manuel Barrios, José María Castroviejo, Carlos María Ydígoras, Medardo Fraile y Santiago Santamaría. Publica también una crítica de un ensayo de Rafael Benítez Claros. 
«Confiamos este encargo en este espacio a la pluma joven de nuestro Francisco Umbral» $»^{23}$.

Así es como Umbral pasa a hacerse cargo de una sección fija cuya temática nada tiene que ver con lo que hasta entonces estaba escribiendo, si bien esboza una línea periodística que va a cultivar a lo largo de su vida: la crónica de la vida cotidiana de nuestro país, no exenta de verdad popular y crítica mordaz. El primer A la llana cultura sale en el mismo número de presentación de la sección- el 293, del 6 de junio de 1964-, con el título «Vuelta ciclista»; el último, un año después, en el número 319 del 5 de junio de 1965, con el título «Nuria». En el ínterin, sin faltar una sola entrega a la cita, Umbral firma un total de veinticuatro textos que hablan, entre otros, de El Cordobés, Soraya o las playas españolas, de los fans o la lotería, y también de Unamuno, los libros o los desarraigados. Lo cierto es que la obligatoriedad de la sección fija va a impedir encontrar durante este periodo otros textos con su firma, salvo en entregas excepcionales en las que incluye alguna crítica literaria o algún texto de creación ${ }^{24}$.

En abril de 1965 surge un nuevo vínculo directo entre La Estafeta y Umbral. A pocos ejemplares de cerrar la «llana cultura», Ponce de Léon le asigna otra participación fija, esta vez en el Itinerario de exposiciones, sección que, como su propio nombre indica, da noticia de las exposiciones que se pueden ver en las distintas salas y pinacotecas de la capital. De este modo, en los números 316, 317 y 319 , de abril, mayo y junio de 1965, Umbral firma en la revista dos secciones diversas.

$\mathrm{Su}$ colaboración en el Itinerario se extiende hasta el ejemplar 342, del 23 de abril de 1966. Dos aspectos caben destacar al respecto: por un lado, la inmersión del escritor en un disciplina artística diferente a la literaria (en este sentido, Umbral tenía sólidos conocimientos de Bellas Artes, por devoción y por preparación); por otro, la elección del pseudónimo LORD como firma para los textos de esta sección; este pseudónimo le acompañará después en su trayectoria ${ }^{25}$, pero en La Estafeta aparecerá casi exclusivamente en el Itinerario.

Durante la segunda mitad de 1965, un Umbral plenamente asentado continúa con la línea marcada, esto es, con colaboraciones en casi todos los números restantes del año, que van de la crónica popular a la crítica literaria; títulos como «El Platanito» o «La dama Ye-Ye» y varias reseñas bibliográficas para Los libros

\footnotetext{
23 «A la llana cultura» (presentación), 293 (6-VI-1964), p. 32.

${ }^{24}$ En los números 311 y 312, de febrero de 1965, incluye sendas reseñas de Efraín Gaitán Orjuela y Alonso de Contreras. Por otra parte, en el número 313, de marzo de ese año, publica el relato «Los que no fuimos de veraneo».

${ }^{25}$ Lo empleará de nuevo, por ejemplo, en sus colaboraciones en los setenta de Hermano Lobo.
} 
así lo demuestran ${ }^{26}$; a ello hay que añadir, obviamente, la crónica artística del Itinerario.

De todo lo dicho hasta ahora, se desprende una clara conclusión: en la primera mitad de esta cuarta época (entre 1962 y 1965), encontramos en La Estafeta a un incansable Umbral que se desdobla en tres: el de la alta cultura, el de la cultura popular y el creador; o dicho de otro modo, el cronista artístico y crítico literario, el valedor de la cultura de la calle y un incipiente famoseo, y el escritor de ficción que, en cuanto puede o se lo permiten, cuela entre las páginas de la revista un relato. Parece, por consiguiente, que periodista y literato empiezan a caminar juntos, no en vano en 1964 Umbral ha obtenido el Premio Nacional de Cuentos Gabriel Miró por Tamouré y en 1965 ha publicado tres obras no periodísticas: el relato Balada de gamberros, su primer volumen de ensayo con título Larra, Anatomía de un dandy, y Tamouré, la antología de cuentos galardonada. Precisamente dos de los tres relatos publicados en La Estafeta se recogen en esta antología: los citados «Mapamundi» $\mathrm{y}$ «El Guateque».

\subsubsection{De 1966 a 1968: El colapso}

1966 comienza como ha terminado el 65, esto es, con la presencia de Umbral en cada ejemplar de La Estafeta y con la diversidad mencionada; así, en los primeros meses del año, junto al Itinerario y reseñas de obras de Aristófanes, Vélez de Guevara o Gonzaléz Ruano, encontramos artículos como «Los microtaxis», «Piedad», «Crónica negra», «La moda Masculina», «El Atleti, campeón»o «Plaza de España».

Un dato interesante de este periodo es la doble entrevista, del 15 de enero, entre Jesús Torbado y el propio Umbral, vencedor y finalista del premio Alfaguara 1965 por las novelas Las corrupciones y Travesía de Madrid respectivamente; la entrevista, que lleva por título «Francisco Umbral pregunta a Jesús Torbado. Jesús Torbado pregunta a Francisco Umbral», respira tensión por ambas partes, lo que no es de extrañar ya que nuestro autor mostró su desacuerdo con el fallo del premio. Dice Anna Caballé al respecto: «El efecto que tuvo la llamada de Jorge Cela, director literario de Alfaguara, a casa de Umbral, para comunicarle que había quedado finalista, no puede saberse, pero sí imaginarse. Su estupor debió de ser absoluto, y la decepción, inmensa» ${ }^{27}$. Pero a decir verdad, el enfado de Umbral se tuvo que ver compensado por la publicación en el mismo año 66 de Travesía de Madrid, novela «perdedora» pero primera en su trayectoria.

\footnotetext{
${ }^{26}$ Reseñas de José Antonio Vizcaíno, Edgar Neville, Raúl Torres, además de las cuatro que incluye en el número doble 322-323 del mes de julio, dedicado al Mapa literario de Galicia, bajo el epígrafe «Cinco libros de camino» (la quinta reseña llevaba la firma de Fernando Ponce).

${ }^{27}$ A. Caballé (2004), p. 200.
} 
Por consiguiente, los meses iniciales de 1966 son, al igual que el 65, de frenética actividad para el autor tanto literaria como periodística. A partir de mayo, sin embargo, esta situación se ve súbitamente frenada en nuestra revista: entre este mes y diciembre, únicamente encontramos cinco textos con su firma, cuatro Cartas desde Madrid, («Donde escribir es berrear», «Que siga siendo Baden-Baden», «Los astronautas de la villa» y «El baile de los menores») y el artículo «La Francisca Sánchez que yo acompañé», publicado en el último número de 1966 (primero de 1967). La escasez continúa durante 1967, año en el que Umbral publica tan solo dos escritos en La Estafeta, dos relatos titulados «Marilén, otoño-invierno», y «Mortal y Rosa», en junio y octubre respectivamente.

La explicación a semejante cambio tiene carácter personal: en 1966 Umbral enferma de una dolencia de carácter neuronal y origen auditivo que le sumerge en continuos vértigos y jaquecas, y le impide escribir ${ }^{28}$; al autor no le queda, por tanto, más remedio que cesar en su actividad. A la enfermedad y al consiguiente parón, el propio Umbral se refiere en dos de los cinco textos estafetianos de la segunda mitad de 1966; por un lado, en «Donde escribir es berrear», una carta a propósito de la nueva ley de Prensa de Manuel Fraga, afirma: «Y he aquí que, habiendo escrito cuanto quise en tiempos de la ley seca, ahora que hay libertad no escribo nada. En parte porque la mano no me sigue, pero quién sabe si no me sigue y pretexta enfermedad porque ella también es del antiguo régimen» ${ }^{29}$. Por otro, en «Que siga siendo Baden-Baden», artículo sobre el verano en Madrid, Umbral explica que puede abordar este tema por eso, porque ha vivido el estío madrileño sentado «en una silla plegable de terraza o de piscina a verlas venir, en un lento viaje hacia la salud, a la busca del tiempo perdido, de los veranos perdidos» ${ }^{30}$.

Pero decíamos que la escasez continúa en 1967. Caballé explica que ese año «no publicará nada más que sus múltiples colaboraciones periodísticas» ${ }^{31}$, situación que, en el caso de La Estafeta, es obvio que no se cumple pues, como se ha señalado, solo hallamos dos únicas aportaciones con su firma. Desconocemos la

\footnotetext{
${ }^{28}$ El escritor lo rememoró en más de una ocasión: «Cuando comenzó la enfermedad mi temor era que fuese algo de origen mental, ya que la cabeza me impedía escribir. Llegué a estar muy desesperado, incluso la idea del suicidio llegó a rondarme; lo peor de todo era no poder escribir» (J. Gracia Armendáriz [2002], p. 53).

${ }^{29}$ F. Umbral, «Donde escribir es berrear», LEL, 346 (18-VI-1966), p. 10.

La carta viene además precedida por una nota de Luis Ponce de León, que asimismo dice: «Francisco Umbral, tan fenomenal escritor y tan amigo nuestro, lleva algún tiempo sin venir por la redacción, enfermo, en su casa y cama. (...) Desde el lecho del dolor Umbral berrea. $\mathrm{Y}$ hay que ver qué bien berrea, qué bien dice, qué bien sufre, imagina y piensa, qué bien escribe» (L. Ponce de León, Nota previa a «Donde escribir es berrear», LEL, 346 [18-VI1966], p. 10).

${ }^{30} \mathrm{~F}$. Umbral, «Que siga siendo Baden-Baden», LEL, 353 (24-IX-1966), p.35.

${ }^{31}$ A. Caballé (2004), pp. 206-207.
} 
causa de la prolongación de este silencio estafetiano pues para mayo de 1967 , Umbral se está restableciendo gracias a un tratamiento con Valium $^{32}$. Ese mismo mes reanuda su colaboración con otros medios como El Norte de Castilla, pero no con el nuestro. ¿Silencio motivado por la redacción de obras no periodísticas? Es posible, ya que en 1968 publica dos nuevos ensayos, Valle Inclán y Lorca, poeta maldito; un extracto del segundo da vida a «Sexo y muerte en García Lorca», el último texto umbraliano en la cuarta época de La Estafeta, en enero de $1968^{33}$.

\subsection{Las contribuciones de Umbral en la quinta época (marzo1968-octubre 1978: números 391-645/646)}

Como se ha señalado previamente, la quinta época de La Estafeta nace el 9 de marzo de 1968 con el número 391, y se extiende hasta octubre de 1978. La revista pasa a ser dirigida por Ramón Solís, quien continúa con igual periodicidad (quincenal) y línea, aunque introduce un interesante cambio: una clara organización interna, que la compartimenta más que nunca:

La Estafeta se edita ahora con un suplemento añadido, el «Estafeta libros», que aporta mayor relevancia a la crítica literaria; el espíritu crítico y analítico se acentúa asimismo en las demás disciplinas culturales, agrupadas en las habituales secciones: «Estafeta arte», «Estafeta cine», «Estafeta música», «Estafeta teatro» ${ }^{34}$.

Aunque esta etapa de la revista se extiende a lo largo de una década, la presencia de Umbral se limita a sus tres primeros años, entre 1968 y 1970. Es fácil intuir que fue Estafeta libros una de las secciones en las que su pluma brilló, y así fue, aunque no con continuidad. La continuidad en cambio sí se vio en una nueva sección que queda en su mano desde el número inaugural de la etapa; igual que en la etapa anterior le habían sido confiadas A la llana cultura y el Itinerario, ahora se le confía, ejemplar a ejemplar, la llamada Crónica de gentes. ¿En qué consiste? Como su propio nombre indica en hablar de gente, de gente noticiable vinculada con el mundo de la cultura; poco que ver, por tanto, con las secciones fijas de la etapa previa.

En un principio la Crónica de gentes se concibió como un conjunto de noticias breves que ofrecieran un panorama de lo que acontecía en las letras hispánicas del momento dentro y fuera de España; sin embargo, a partir del número 399 (del 1 de julio de 1968), la estructura de la sección cambió ligeramente al dar cabida a un artículo más extenso, centrado en un escritor o en un grupo de ellos. De este modo, Umbral lo mismo hablaba de individualidades como Menéndez Pidal, González

\footnotetext{
${ }^{32}$ A. Caballé (2004), p. 210.

${ }^{33}$ Se trata del capítulo séptimo, titulado «Canciones».

${ }^{34}$ M. Garbisu (2010), p. 85.
} 
Ruano, Cela o Aldecoa, que de colectivos como el de las escritoras, los relatistas, los articulistas, los noveles y los Nobeles, o el de los autores con barba, los que visten elegantes o los merecedores de una calle. La sección se mantuvo puntual hasta el ejemplar 421 del 1 de junio de 1969; después permaneció, sinuosa, hasta el ejemplar 442 del 15 de abril de 1970.

Si bien los textos literarios, a caballo entre el artículo y la crónica, eran habituales en Umbral, se puede afirmar que esta sección confirma al autor como cronista fundamental de la literatura más o menos actual de nuestro país. Por ello Anna Caballé afirma que la crónica literaria es uno de los géneros que destacan entre las colaboraciones de Umbral en La Estafeta, junto con la creación (en esto último recordemos que coincide con Gracia Armendaríz) ${ }^{35}$.

El matrimonio de Umbral con la Crónica de gentes no significa que no lo encontremos en otras lides, en entregas sin la sección o con dos textos en un mismo ejemplar; en este sentido, la reseña, el artículo y la entrevista son -además, claro, de la crónica- los géneros más frecuentes en esta etapa. Respecto al primero, ya se ha adelantado que su firma aparece a menudo en la sección Estafeta libros; un total de ocho textos así lo confirma, en la que sigue siendo tendencia habitual del escritor en la revista ${ }^{36}$. Respecto a los dos géneros restantes, por el contrario, se intuye ahora a un Umbral más extenso y profundo que en etapas anteriores: por un lado, artículos y reportajes centrados en el análisis literario, como los dedicados García Nieto y a Valle-Inclán, en octubre y diciembre de 1968, o a George Sand y la Beat Generation (lo foráneo gana cada vez más terreno), en agosto y diciembre de 1969; por otro, interesantes entrevistas, originales en planteamiento y estructura, frescas y espontáneas, en las que Umbral charla con Indro Montanelli, José María Sánchez Silva, Dámaso Alonso, Álvaro Cunquiero, Eduardo Zamacois, Dámaso Santos, Luis Rosales, Medardo Fraile o Corpus Barga; son casi siempre encuentros que vienen marcados por un acontecimiento: por ejemplo, la jubilación de Dámaso Alonso, la concesión del Nadal a Cunqueiro o el temporal regreso a España de Zamacois. Curiosamente, para una de estas entrevistas recupera el pseudónimo LORD, para la dedicada a Vicente Aleixandre, del número 400 de julio de $1968^{37}$.

La gran parte de ellas se publican a lo largo de 1969, el mismo año en que Umbral se adentra en otros campos del conocimiento, de nuevo en las bellas artes y, de nuevas, en la lingüística; en el primero, a través también de una serie de entrevistas a artistas como Manuel Viola, Juan Barjola o José Vela Zanetti (lejos han quedado las crónicas del Itinerario); en el segundo, a través de colaboraciones esporádicas en El idioma nuestro de cada día, sección fija de la quinta etapa con

\footnotetext{
${ }^{35}$ A. Caballé (2004), p. 188.

${ }^{36}$ Reseñas de Miguel Delibes, José María Gironella, Juan Perucho, Luis Ortega, Umberto Eco, Alonso Zamora Vicente y Juan-Jacobo Barjalía.

${ }^{37}$ Emplea también este pseudónimo en un reportaje dedicado a la feria del libro de Madrid: «XXVII Feria Nacional del libro», 398 (15-VI-1968), pp. 20-23.
} 
artículos lingüísticos que, «sin "gramatequerías" enojosas, siga de cerca la evolución del idioma nuestro de cada día, que es "esa cosa" que se está haciendo continuamente en la calle, entre la gente, en la pluralidad de las hablas peninsulares, insulares y ultramarinas ${ }^{38}$. Umbral firma cinco colaboraciones, la primera de ellas en julio de 1969, y las cuatro restantes en meses alternos de 1970, una vez finalizada la Crónica de gentes y cuando su presencia en La Estafeta está ya languideciendo. De hecho el escrito postrero del colaborador en la revista pertenece a esta sección: se titula «El piropo» y aparece en el número 452 del 15 de septiembre de ese año.

Esta es, en general, la tendencia de la quinta época, algo distinta, como se ve, a la de la etapa anterior ya que, a excepción de la crítica literaria, que se mantiene en ambas, las colaboraciones difieren en tono y tema de una fase a otra. Ahora en la quinta, con la Crónica de gentes, los artículos y las entrevistas, prevalece el que hemos llamado Umbral de la alta cultura; sin embargo el creador y el de la «cultura llana» de la era de Ponce prácticamente han desaparecido. Un único texto al respecto de cada faceta mantiene estas tendencias: un relato titulado «Niña, mi niñanáusea», de mayo de 1968, y un escrito dedicado a «Marisol (sociología de una ninfa)», de junio de 1969.

\section{Conclusiones}

Expuestos ya los datos, intentemos poner orden en el marasmo: tres etapas, nueve años y casi doscientos textos; ¿se puede presumir una tendencia? Sí, sin duda alguna, tanto cuantitativa como cualitativa.

Porque si en la tercera época, los textos con su firma no suman más de un docena, en la cuarta la cifra se multiplica por nueve, aunque con las particularidades ya expuestas: de los siete años que abarca la etapa (1962-1968), la presencia de Francisco Umbral es constante en los cuatro iniciales mientras que se eclipsa en los finales. En la quinta época los altibajos cesan pues en sus dos primeros años (entre el 9 de marzo de 1968 y el 1 de mayo de 1970) y a excepción de los ejemplares 423 y $440^{39}$, el autor imprime su firma concretamente en setenta y un escritos, y en todas las entregas. Después las aportaciones empiezan a escasear y el adiós definitivo a atisbarse: entre junio y septiembre de 1970, tan solo saca cuatro textos,

38 «El idioma de cada día» (Presentación), LEL, 391 (9-III-1968), p. 40. Esta sección aparece desde la primera entrega de la quinta etapa, en la contraportada, y se mantiene hasta el ejemplar 458, del 15 de diciembre de 1970. Sus firmas más asiduas son las de Gerardo Diego y Joaquín de Entrambasaguas.

La profesora Pilar Fernández ha realizado un exhaustivo estudio de esta sección en el capítulo «El idioma nuestro de cada día: análisis del lenguaje en la quinta etapa de $L a$ Estafeta Literaria» (en VV.AA.: La Estafeta Literaria y su contribución a la difusión de de la cultura del siglo XX, Madrid, Sílex, 2010, pp. 11-62).

${ }^{39}$ Del 1 de junio de 1969 y 15 de marzo de 1970 respectivamente. 
la entrevista a Corpus Barga y tres colaboraciones para El idioma nuestro de cada día, todos previamente citados. En definitiva, entre la primera y la última colaboración continuada de Umbral en La Estafeta -entre «Hacia una nueva épica» del 1 de noviembre de 1961 y «El piropo» 15 de septiembre de 1970- han transcurrido 194 textos y casi nueve años.

Nueve años en los que su implicación con la revista ha ido in crescendo, lo mismo que la riqueza de sus aportaciones; en los que ha abarcado todos los géneros, artículo, crónica, entrevista o crítica; en los que ha pasado del suelto a la sección fija y de lo popular a lo culto; en los que ha interpretado y narrado la vida literaria española de antes y ahora; en los que sus relatos han sobrevolado por la revista y en los que la crítica literaria se ha mantenido constante en las tres épocas, se llamara como se llamara la sección de libros que la cobijaba. ¿Hay que dar entonces la razón a Gracia Armendariz cuando afirmaba que fue La Estafeta una «las publicaciones especializadas donde Umbral consigue dar a la luz un mayor número de textos de creación y de crítica de poesía»? Sí y no; sí, porque del medio centenar de relatos que Umbral escribió a lo largo de su trayectoria, siete de ellos fueron recogidos en La Estafeta ${ }^{40}$ y no, porque en su labor constante como crítico de la revista, firmó más reseñas sobre narrativa o ensayo que sobre lírica. ¿Y hay que dar la razón a Anna Caballé cuando consideró que la crónica se unía a la creación en la balanza umbraliana de La Estafeta? Aquí la respuesta es afirmativa ya que, sin duda, de la mano de Umbral este género brilló en la cuarta y quinta época, con dos secciones y disciplinas diversas: las bellas artes del Itinerario y la literatura de la Crónica de gentes, pero también con la multitud de textos sueltos que escribió sobre la vida literaria española.

Después de estos nueve años, Francisco Umbral y La Estafeta Literaria continúan sus caminos por separado, aunque estos nuevamente se cruzan en tres ocasiones, en 1974, en 1976 y en 1980, cuando aparecen tres textos del escritor en la revista: un relato bellamente titulado «Soy la soledad que toca el xilofón para pagar el alquiler», el artículo «Los Catalanes», recogido en Con pluma ajena, sección que reproduce textos publicados en otros medios nacionales ${ }^{41}$, y el

${ }^{40}$ El propio Umbral afirmó lo siguiente: «El medio centenar de cuentos que más o menos habré escrito en mi vida está repartido por los periódicos y revistas nacionales» (F. Umbral [1977], p. 16). Los relatos que Umbral publicó en La Estafeta son los siguientes: Mapamundi, El guateque, Los que no fuimos de veraneo, Marilén, otoño-invierno, Mortal y rosa, Niña, mi niña-náusea y Soy la soledad que toca el xilofón para pagar el alquiler. Umbral incorporó los dos primeros (Mapamundi y El guateque) en su antología Tamouré (1965); y Marilén, otoño- invierno, en Las vírgenes (1969).

${ }^{41}$ «Soy la soledad...» se corresponde, como señala Anna Caballé, con el autorretrato inicial de la novela Mortal y rosa (2004, p. 260) En cuanto a «Los catalanes», se trata de un texto publicado en Diario de un snob, la célebre sección que Umbral firmó en El País. 
previamente citado fragmento de Los helechos arborescentes, ya en la sexta etapa de la revista o Nueva Estafeta.

Estos tres títulos finales se convierten en símbolo y explicación de todo. ¿Por qué Umbral abandona en 1970 La Estafeta Literaria? La respuesta la hemos esbozado desde un principio; porque en 1969, contratado por la agencia Colpisa, da el salto definitivo al artículo diario, pero también porque en los años de la quinta etapa estafetiana su actividad creadora se ha multiplicado. Los últimos títulos que, en este sentido, hemos mencionado han sido Lorca, poeta maldito y Valle-Inclán, ensayos de 1968; pero es que en 1969, Umbral saca a la luz el compendio de cuentos Las vírgenes, la novela Si hubiéramos sabido que el amor era eso y una biografía sobre Lord Byron; y en 1970, las novelas Las europeas y El Giocondo, y el ensayo Miguel Delibes.

A partir de este momento esta va ser la media de producción del autor: varios libros al año, su artículo diario y otras colaboraciones periodísticas semanales; a ello se une su vida pública, cada día -valga la repetición- más pública. Ya que el escritor que en 1961 llegó a Madrid al asalto de la Puerta del Sol, diez años después ha conquistado, con sus artículos y su literatura, la capital, las provincias, el país entero. 


\section{ANEXO. Índice de títulos de Umbral en La Estafeta Literaria a lo largo de sus etapas}

Total de colaboraciones: 198

Tercera época (noviembre 1957- septiembre1962: números 104-249)

$\begin{array}{ll}\text { Total de colaboraciones: } & 12 \\ \text { Secciones: Libros: } & 4 \\ \text { Varios: } & \end{array}$

\section{9}

- «Eugenio D’Ors, maestro imposible», 183 (15-XII- 1959), p. 6.

\section{1}

- «Hacia una nueva épica», 228 (1-XI-1961), p. 11.

\section{2}

- «Asalto a la Puerta del Sol», 235 (15-II-1962) p. 14.

- «Compromiso y deserción», 238 (1-IV-1962), p. 14.

- «Novela». Reseña de Máximo Regidor: El pan muerto. Sección Libros, 243 (15-VI-1962), p. 20.

- «Castilla y los escritores», 244 (1-VII-1962), p. 11.

- «Ensayo». Reseña de Heinz Häfner: Vivencia de la culpa y conciencia. Sección Libros, 245 (15-VII-1962), p. 21.

- «Ensayo». Reseña de Lorenz Jaeger: Concilio, iglesia, cristiandad. Sección Libros, 245 (15-VII-1962), p. 21.

- «Relato breve». Reseña de José Acosta Montoro: Relatos de la tierra ardiente. Sección Libros, 245 (15-VII-1962), p. 22.

- «Rilke, en España», 248 (1-IX-1962), p. 5.

- «Asedio a la juventud», 249 (15-IX-1962), p. 7.

- «Leopoldo Panero y la generación del 36», 249 (15-IX-1962), p. 14.

Cuarta época (octubre 1962-febrero 1968: números 250-390)

Total de colaboraciones:

Secciones:

Los libros (o Los libros. Más allá de las portadas - Las gafas sin cristal. Los libros):

Literatura viajera:

Correspondencias:

Estafeta de las provincias

(o Estafeta breve de las provincias):

Los Ateneos:

A la llana cultura:

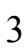

Itinerario de exposiciones:

4
1
26
16


$\begin{array}{ll}\text { Dos cartas desde Madrid y una de Córdoba: } & 1 \\ \text { Principio quieren las cosas: } & 1 \\ \text { Varios: } & \end{array}$

\section{1} 33

\section{2}

- Reseña de Juan García Yagüe: Familia y personalidad, 250 (I Octubre 1962), p. 15.

- «Gerardo Diego en el café», 250 (I Octubre -1962), p. 21.

- «Oficios y beneficios del escritor», 251 (II Octubre-1962), p. 19.

- «Libros españoles para los niños del mundo». Sección Los libros, 254 (I Diciembre-1962), p.17.

\section{3}

- «Horóscopo literario para 1963», 256 (5-I-1963), p. 3.

- «Mapamundi». Sección Literatura viajera, 257 (19-I-1963), pp.12-13 - Ficción.

- «Ramón, inhumado en Madrid». Sección Correspondencias, 258, (2-II1963), pp. 2, 23.

- «Cela en el Ateneo». Sección Correspondencias, 258 (2-II-1963), p. 23.

- «Carta de Madrid. Cerrado por reforma». Sección Estafeta de las provincias, 260 (2-III-1963), p. 24.

- «La polémica del jaz», 262 (30-III-1963), pp. 6-7.

- «Pascua florida en las revistas», 263 (13-IV-1963), pp. 10-11.

- «Eutrapelia intencionada sobre el compromiso del escritor. Derechos del escritor y derechos de la mujer», 266 (25-V-1963), p. 3.

- «Literatura y opresión», 268 (22-VI-1963) p. 2.

- «Diálogo ante el museo», 271 (3-VIII-1963), p. 6.

- «La Escuela periodística del Norte de Castilla», 272-273 (17-VIII-1963), pp. 30-31.

- «El guateque», 272-273 (17-VIII-1963), pp. 50-52 - Ficción.

- «Escribas y fariseos», 275 (28-IX-1963), p. 5.

- «Poesía. Juan Ramón, inédito» Sección: Los libros, 279 (23-XI-1963), p. 19.

- «Desde antes de Roma. Con faldas y no tan a lo loco», 280 (7-XII-1963), p. 3.

1964

- «Las novelas de la Restauración», 282-283 (4/18-I-1964), pp. 45-46.

- «Narración. Cela: del garito al salón». Reseña de Camilo José Cela: Garito de hospicianos. . Sección: Los libros, 284 (1-II-1964), p. 20.

- «Narración. Cela: del garito al salón». Reseña de Camilo José Cela: Toreo de salón. Farsa con acompañamiento de clamor y murga. Sección: Los libros, 284 (1-II-1964), p. 20.

- «El horóscopo tenía razón», 285 (15-II-1964), p. 3.

- «Narración». Reseña de Manuel Barrios: El crimen. Sección: Los libros, 
290 (25-IV-1964), p. 20.

- «El sitio vacío», 291 (9-V-1964), p. 12.

- «Ensayo». Reseña de Rafael Benítez Claros: Visión de la literatura española. Sección: Los libros, 291 (9-V-1964), p. 19.

- «Narración». Reseña de José María Castroviejo: Los paisajes iluminados. Sección: Los libros, 291 (9-V-1964), p. 19.

- «Narración». Reseña de Carlos María Ydígoras: Algunos no hemos muerto. Sección: Los libros, 292 (23-V-1964), p. 21.

- «Un libro sobre la mesa. Eugenio D’Ors». Sección: Los Ateneos. El de Madrid, 292 (23-V-1964), p. 24.

- «Narración». Reseña de Medardo Fraile: Cuentos de verdad. Sección: Los libros. Más allá de las portadas, 293 (6-VI-1964), p. 20.

- «Narración». Reseña de Santiago Santamaría: La diosa y su venganza. Sección: Los libros. Más allá de las portadas, 293 (6-VI-1964), p. 21.

- «Vuelta ciclista». Sección: A la llana cultura, 293 (6-VI-1964), p. 32.

- «El cordobés, mito». Sección: A la llana cultura, 294 (20-VI-1964), p. 32.

- «Valdeajos». Sección: A la llana cultura, 295 (4-VII-1964), p. 30.

- «La ex saeta rubia». Sección: A la llana cultura, 296 (18-VII-1964), p. 31.

- «Sociología del bikini». Sección: A la llana cultura, 297 (1-VIII-1964), p. 32.

- «No tiene edad». Sección: A la llana cultura, 298 (15-VIII-1964), p. 32.

- «Soraya Y el SoraYismo». Sección: A la llana cultura, 299 (29-VIII-1964), p. 32.

- «El hereje Unamuno». Sección: A la llana cultura, 300-301 (12/26-IX-1964), p. 81.

- «Los de Alemania». Sección: A la llana cultura, 302, (10-X-1964), p. 31.

- «El corazón olímpico». Sección: A la llana cultura, 303 (26-X-1964), p. 31.

- «Los Fans». Sección: A la llana cultura, 304 (7-XI-1964), p. 30.

- «La lotería». Sección: A la llana cultura, 305 (21-XI-1964), p. 31.

- «El bacilo literario». Sección: A la llana cultura, 306 (5-XII-1964), p. 30.

- «Los protagonistas». Sección: A la llana cultura, 307 (19-XII-1964), p. 32.

\section{5}

- Sin título. Sección: A la llana cultura, 308 (2-I-1965), p. 32.

- «Andalucía, sin teorías». Sección: A la llana cultura, 309 (16-I-1965), p. 19.

- «El agua». Sección: A la llana cultura, 310 (30-I-1965), p. 20.

- «Ensayo». Reseña de Efraín Gaitán Orjuela. C.M.F.: La clave del éxito periodístico. Sección: Las gafas sin cristal. Los libros, 311 (13-II-1965), pp. 12-13.

- «El Seat 600». Sección: A la llana cultura, 311 (13-II-1965), p. 20.

- «Narración». Reseña de Alonso de Contreras: Vida del Capitán Alonso de Contreras. Sección: Las gafas sin cristal. Los libros, 312 (27-II-1965), pp. 
12-13.

- «Las que tiene que limpiar». Sección: A la llana cultura, 312 (27-II-1965), p. 20.

- «Por los codos». Sección: A la llana cultura, 313 (13-III-1965), p. 20.

- «Los que no fuimos de veraneo», 313 (13-III-1965), pp. 30-32-Ficción.

- «Los desarraigados». Sección: A la llana cultura, 314 (27-III-1965), p. 20.

- «Locos, bajitos y analfabetos». Sección: A la llana cultura, 315 (10-IV1965), p. 20.

- «Los turistas». Sección: A la llana cultura, 316, (24-IV-1965), p. 21.

- «La España de cada provincia - Rafael Zabaleta». Sección: Itinerario de exposiciones, 316, (24-IV-1965), p. 24. Por LORD

- «Antonio Suárez - González de la Torre - Iranzo - Juan Guillermo». Sección: Itinerario de exposiciones, 317 (8-V-1965), pp. 11-12. Por LORD

- «La romería del libro». Sección: A la llana cultura, 317 (8-V-1965), p. 20.

- «El libro en la calle». Sección: A la llana cultura, 318 (22-V-1965), p. 20.

- «La XXIV Feria Nacional del libro». Sección: Itinerario de exposiciones, 319 (5-VI-1965), pp. 3-6. Por LORD

- «Nuria». Sección: A la llana cultura, 319 (5-VI-1965), p. 20.

- «Galicia en cuatro libros». Reseña de José Antonio Vizcaíno: De Roncesvalles a Compostela. Sección: Los libros, 320-321 (19-VI/3-VII1965), pp. 70-71.

- «Complicantes y esclarecedores», 322-323 (17/31-VII-1965), p. 112.

- «Cinco libros de camino...». Reseña de J. Subias Galter: Las rutas del Románico. Sección: Los libros, 322-323 (17/31-VII-1965), pp. 160-161.

- «Cinco libros de camino...». Reseña de Arsenio Fernández Arenas y Pablo Huarte Arana: Los caminos de Santiago. La poligraja. Sección: Los libros, 322-323 (17/31-VII-1965), p. 161.

- «Cinco libros de camino...». Reseña de Millán Clemente de Diego: Andando por el Camino de Santiago. Sección: Los libros, 322-323 (17/31VII-1965), p. 161.

- «Cinco libros de camino...». Reseña de Vicente Martínez: El Camino de Santiago. (Diario de un peregrino). Sección: Los libros, 322-323 (17/31VII-1965), pp. 161-162.

- «Charlot, ¿último romántico?», 326 (11-IX-1965), p. 34.

- «El Platanito», 328 (9-X-1965), p. 14.

- «Santamaría - Grabados argentinos - Isabel Boutier - Ibiza, 65». Sección: Itinerario de exposiciones, 328 (9-X-1965), p. 11. Por LORD.

- «Narración». Reseña de Edgar Neville: El día más largo de monsieur Marcel. Sección: Las gafas sin cristal. Los libros, 328 (9-X-1965), p. 20.

- «Yraola - Roca Fuster». Sección: Itinerario de exposiciones, 329 (22-X1965), p. 12. Por LORD.

- «Gitanerías», 329 (22-X-1965), p. 28. 
- «María Antonia Dans - Ulbricht». Sección: Itinerario de exposiciones, 330 (6-XI-1965), p. 13. Por LORD.

- «La dama Ye-Ye», 331 (20-XI-1965), p. 13.

- «Núñez Larraz - Viola». Sección: Itinerario de exposiciones, 331 (20-XI1965), p. 17. Por LORD.

- «Arias - Julio Hernández - Blardony - Caty Juan». Sección: Itinerario de exposiciones, 332 (4-XII-1965), p. 16. Por LORD

- $\quad$ «Trepat - Barjola - Pepi Sánchez». Sección: Itinerario de exposiciones, 333 (18-XII-1965), p. 17. Por LORD.

- «Narración». Reseña de Raúl Torres: Escucho un breve ruido. Sección: Las gafas sin cristal. Los libros, 333 (18-XII-1965), p. 18.

\section{6}

- «Jaime Ferrán: un ángel en Colombia», 334 (1-I-1966), p. 26 - Entrevista.

- «Ayça y Devrim Erbil - Gerardo Rueda - Estruga, Orts, Alcain». Sección: Itinerario de exposiciones, 334 (1-I-1966), p. 39. Por LORD

- «Los microtaxis», 334 (1-I-1966), p. 35.

- «Perceval - Villaseñor - Victoria». Sección: Itinerario de exposiciones, 335 (15-I-1966), p. 17. Por LORD.

- «Ensayo». Reseña de C. González-Ruano: Mis queridas mujeres. Sección: Las gafas sin cristal. Los libros, 335 (15-I-1966), pp. 19-20.

- «Después de Reyes», 335, (15-I-1966), p. 27.

- «Francisco Umbral pregunta a Jesús Torbado. Jesús Torbado pregunta a Francisco Umbral». Sección: Correspondencias, 335 (15-I-1966), pp. 3637.

- «Paulino Vicente - Peinado - Amador». Sección: Itinerario de exposiciones, 336 (29-I-1966), p. 39. Por LORD

- «Piedad», 336 (29-I-1966), p. 39.

- «Crónica negra», 337 (12-II-1966), p. 18.

- «Serny - Omar Rayo - Círculo de acuarelistas de México - Julio Antonio». Sección: Itinerario de exposiciones, 338 (26-II-1966), p. 18. Por LORD

- «Temas clásicos: las mujeres y el diablo». Reseña de Aristófanes: Comedias (Lisistrata y la asamblea de las mujeres). Sección: Las gafas sin cristal. Los libros, 338 (26-II-1966), p. 21.

- «Temas clásicos: las mujeres y el diablo». Reseña de Luis Vélez de Guevara: El diablo cojuelo. Sección: Las gafas sin cristal. Los libros, 338 (26-II-1966), pp. 21-22.

- «Trece pintores». Sección: Itinerario de exposiciones, 340 (26-III-1966), p. 18. Por LORD.

- «La moda masculina», 340 (26-III-1966), p. 40.

- «El Atleti, campeón», 341 (9-IV-1966), p. 12.

- «Tres pintores y Pepa Osorio». Sección: Itinerario de exposiciones, 341 (9IV-1966), p. 29. Por LORD. 
- «Plaza de España», 342 (23-IV-1966), p. 8.

- «Esmaltes, gouachés, grabados y cerámicas». Sección: Itinerario de exposiciones, 342 (23-IV-1966), p. 14. Por LORD

- «Donde escribir es berrear». Sección: Dos cartas desde Madrid y una de Córdoba .Carta de Madrid, 346 (18-VI-1966), p. 10.

- «Que siga siendo Baden-Baden». Sección: Carta desde Madrid. Estafeta breve de las provincias, 353 (24-IX-1966), p. 35.

- «Los astronautas de la villa». Sección: Carta desde Madrid. Estafeta breve de las provincias, 354 (8-X-1966), p. 34.

- «El baile de los menores». Sección: Carta desde Madrid. Estafeta breve de 1967 las provincias, 357 (19-XI-1966), p. 34.

- «La Francisca Sánchez que yo acompañé», 360-361 (31-XII-1966/14-I1967), pp. 18-19.

- «Marilén, otoño-invierno», 371 (3-VI-1967), p. 23 - Ficción.

- «Mortal y Rosa». Sección: Principio quieren las cosas, 381-382 (21-X/4XI-1967), p. 71 - Ficción.

1968

- «Sexo y muerte en García Lorca», 387 (13-I-1968), pp. 16-17.

Quinta época (marzo 1968- octubre 1978: números 391-645/646)

Total de colaboraciones:

Secciones:

Crónica de gentes: $\quad 37$

Estafeta libros: $\quad 8$

El idioma nuestro de cada día: $\quad 5$

El escritor, al día: $\quad 1$

Pliegos sueltos de La Estafeta: $\quad 1$

Varios:

Con pluma ajena: $\quad 1$

\section{8}

- «Crónica de gentes», 391 (9-III-1968), pp. 12-13.

- «Lo que lee Madrid», 391 (9-III-1968), pp. 20-23.

- «Crónica de gentes», 392 (23-III-1968), pp. 14-15.

- «Crónica de gentes», 393 (6-IV-1968), pp. 12-13.

- 《Crónica de gentes», 394 (20-IV-1968), pp. 14-15.

- «Crónica de gentes», 395, 4-V-1968, pp. 14-15.

- «Niña, mi niña-náusea», 395 (4-V-1968), pp. 17-18 - Ficción.

- «Crónica de gentes», 396 (18-V-1968), pp. 14-15.

- «Indro Montanelli», 396 (18-V-1968), pp. 20-22 - Entrevista. 
- «Narración, periodismo». Reseña de Miguel Delibes: Vivir al día. Sección: Estafeta libros, 396 (18-V-1968), p. 36.

- «Crónica de gentes», 397 (1-VI-1968), pp. 14-15.

- «Los escritores y el Marca». Sección: Crónica de gentes, 398 (15-VI1968), p. 10.

- «Promoción cultural en tres dimensiones». Sección: Crónica de gentes, 398 (15-VI-1968), p. 10.

- «Cinegética, viajes, folklore». Reseña de José María Gironella: En Asia se muere bajo las estrellas. Sección: Estafeta libros, 398 (15-VI-1968), pp. 3-4.

- «XXVII Feria Nacional del libro», 398 (15-VI-1968), pp. 20-23. Por LORD.

- «Los últimos legitimistas del café con leche». Sección: Crónica de gentes, 399 (1-VII-1968), p. 16.

- «Encuentro (horizontal) con Vicente Aleixandre», 400 (15-VII-1968), pp. 10-11 - Entrevista. Por LORD.

- «El escritor de provincias». Sección: Crónica de gentes, 401 (1-VIII-1968), p. 9.

- «Serenos y escritores». Sección: Crónica de gentes, 402-403-404 (15VIII/15-IX-1968), p. 91.

- «José García Nieto, entre Garcilaso y Luis Cernuda», 405 (1-X-1968), pp. 11-12.

- «Las escritoras. Sección: Crónica de gentes, 405 (1-X-1968), p. 39.

- 《J.M. Sánchez Silva», 406 (15-X-1968), p. 14-15 - Entrevista.

- 《Los estrenistas». Sección: Crónica de gentes, 406 (15-X-1968), p. 39.

- «Los narradores en corto». Sección: Crónica de gentes, 407 (1-XI-1968, pp. 38-39).

- «Los mantenedores». Sección: Crónica de gentes, 408 (15-XI-1968), p. 15.

- «Dámaso Alonso», 409 (1-XII-1968), pp. 10-11 - Entrevista.

- «Don Ramón». Sección: Crónica de gentes, 409 (1-XII-1968), p. 39.

- «Dramatis Personae de Valle Inclán», 410 (15-XII-1968), pp. 8-9.

- «C.G.R.». Sección: Crónica de gentes, 410 (15-XII-1968), p. 11.

\section{9}

- «Los alucinados». Sección: Crónica de gentes, 411 (1-I-1969), p. 37.

- «Manuel Viola descubre América», 412 (15-I-1969), pp. 12-14 - Entrevista.

- «Los costumbristas». Sección: Crónica de gentes, 412 (15-I-1969), p. 37.

- $\quad$ «Estética de hoy». Reseña de Juan Perucho: La cultura y el mundo visual. Sección: Estafeta libros, 412 (15-I-1969), pp. 91-92.

- $\quad$ "Amor de varias clases». Reseña de Juan Perucho: La sonrisa de Eros. Sección: Estafeta libros, 412 (15-I-1969), pp. 93-94.

- «Todo Álvaro Cunqueiro», 413 (1-II-1969), pp. 8-9 - Entrevista.

- «Los solterones». Sección: Crónica de gentes, 413 (1-II-1969), p. 15.

- «Los elegantes». Sección: Crónica de gentes, 414 (15-II-1969), p. 12.

- «El nuevo Bululú: varieté en La Corrala», 414 (15-II-1969), pp. 18-19. 
- «Ley, drogas y muerte». Reseña de Luis Ortega: Adicciones, vicios y estimulantes. Sección: Estafeta libros, 414 (15-II-1969), p. 110.

- «Escritores con calle». Sección: Crónica de gentes, 415 (1-III-1969), p. 25.

- «Vela Zanetti, en su pueblo», 416 (15-III-1969), pp. 6-8 - Entrevista.

- «Los articulistas». Sección: Crónica de gentes, 416 (15-III-1969), p. 38.

- «Postales, fantasía y ensayos». Reseña de Umberto Eco: Apocalípticos e integrados ante la cultura de masas. Sección: Estafeta libros, 416 (15-III1969), pp. 122-123.

- «Los noveles». Sección: Crónica de gentes, 417 (1-IV-1969), p. 9.

- «El mal escritor». Sección: Crónica de gentes, 418 (15-IV-1969), p. 13.

- «Ensayismo literario». Reseña de Alonso Zamora Vicente: La realidad esperpéntica (Aproximación a Luces de Bohemia). Sección: Estafeta libros, 418 (15-IV-1969), p. 138.

- «Juan Barjola: "Yo no he copiado a Bacon”», 419 (1-V-1969), pp. 12-13 Entrevista.

- «Escritores con barba». Sección: Crónica de gentes, 419 (1-V-1969), p. 39.

- «Con Zamacóis, a la busca del Madrid perdido», 420 (15-V-1969), pp. 4-7

- Entrevista.

- «Doña Matilde». Sección: Crónica de gentes, 421 (1-VI-1969), p. 11.

- «Marisol. (Sociología de una ninfa)», 422 (15-VI-1969), pp. 4-8.

- «Rotativo caraqueño afrenta academia». Sección: El idioma nuestro de cada dia, 424 (15-VII-1969), p. 40.

- «Laclos, el libertino». Sección: Crónica de gentes , 425 (1-VIII-1969), p. 16.

- «Georg Sand en Mallorca», 426-427-428 (15-VIII/15-IX-1969), p. 25.

- «Los mecenas». Sección: Crónica de gentes, 429 (1-X-1969), p. 10.

- «C.J.C.». Sección: Crónica de gentes, 430 (15-X-1969), p. 13.

- «Nuestros Nobel». Sección: Crónica de gentes, 431 (1-XI-1969), p. 12.

- «Dámaso Santos, hombre de letras», 431 (1-XI-1969), pp. 18-19 Entrevista.

- «Los desmitificados». Sección: Crónica de gentes, 432 (15-XI-1969), p. 9.

- «En la muerte de Ignacio Aldecoa». Sección: Crónica de gentes, 433 (1XII-1969), p. 12.

- «Réquiem por la "Beat Generation" (en la muerte de Jack Kerouac, alcohólico y pionero)», 433 (1-XII-1969), pp. 18-20.

- «Luis Rosales», 434 (15-XII-1969), pp. 18-20 - Entrevista.

\section{0}

- «¿Por qué se escriben artículos de periódico?», 435 (1-I-1970), pp. 8-9.

- «Francisco García Pavón (Premio Nadal, 1969)». Sección: El escritor, al dia, 436 (15-I-1970), pp. 8-9 - Entrevista.

- «La fotografías de Alfonso», 437 (1-II-1970), pp. 18-20.

- «Escritores “Camp”». Sección: Crónica de gentes, 438 (15-II-1970), p. 25. 
- «Las heroínas». Sección: Crónica de gentes, 439 (1-III-1970), p. 15.

- $\quad$ «De podadera a Madariaga». Sección: El idioma nuestro de cada día, 441 (1-IV-1970), p. 40.

- «Mauricio Bacarisse». Sección: Crónica de gentes, 442 (15-IV-1970), p. 9.

- «Narrativa actual». Reseña de Juan-Jacobo Barjalía: Historias de monstruos. Sección: Estafeta libros, 442 (15-IV-1970), p. 300.

- «Medardo Fraile entre los hippies», 443 (1-V-1970), pp. 18-20 - Entrevista.

- «Corpus Barga, ni raro ni olvidado», 446 (15-VI-1970), pp. 16-17 Entrevista.

- «Las suecas». Sección: El idioma nuestro de cada día, 447 (1-VII-1970), p. 40 .

- «Los americanismos». Sección: El idioma nuestro de cada día, 449 (1-VIII1970), p. 40.

- «El piropo». Sección: El idioma nuestro de cada día, 452 (15-IX-1970), p. 40.

1974

- «Soy la soledad que toca el xilofón para pagar el alquiler». Sección: Pliegos sueltos de La Estafeta, 554 (15-XII-1974), p. 76 - Ficción.

1976

- «Diario de un snob. Los catalanes». Sección: Con pluma ajena,590 (15-VI1976), p. 6.

Sexta época: Nueva Estafeta (diciembre 1978- junio 1983)

Total de colaboraciones: $\quad 1$

1980

- «Los helechos arborescentes (fragmento)», 17 (Abril 1980), pp. 18-25 Ficción.

\section{Obras citadas}

CABALLÉ, Anna: Francisco Umbral. El frío de una vida, Madrid, Espasa Calpe, 2004.

FERNÁNDEZ, Pilar: «El idioma nuestro de cada día: análisis del lenguaje en la quinta etapa de La Estafeta Literaria», en VV.AA.: La Estafeta Literaria y su contribución a la difusión de de la cultura del siglo XX, Madrid, Sílex, 2010, pp. $11-62$.

FERNÁNDEZ-SANDE, M. y E. MARTÏNEZ RICO: «Primeras colaboraciones periodísticas y literaris de Francisco Umbral, textos recobrados: Diario Proa y 
revista Arco (1954-1956)», Estudios sobre el Mensaje Periodístico, XX, 1 (2014), pp. 357-376.

GARBISU, Margarita: «La literatura extranjera en La Estafeta Literaria: 1957 y Rafeal Morales como punto de inflexión», en VV.AA.: La Estafeta Literaria y su contribución a la difusión de la cultura del siglo XX, Madrid, Sílex, 2010, pp. 63-101.

GARBISU BUESA, Margarita; IGLESIAS BERZAL, Montserrat: Índices de La Estafeta Literaria (1944-2001). Contenidos literarios de la revista, Madrid, Fragua, 2004.

GRACIA ARMENDARIZ, Juan: El artículo diario de Francisco Umbral (19571988): Análisis y documentación, Madrid, Universidad Complutense, 2002. [Recurso electrónicos: http://eprints.ucm.es/tesis/19911996/S/3/S3012301.pdf]

-----: «Orígenes al artículo diario de Francisco Umbral. Los años de formación, 1957-1969», en ARDAVÍN, Carlos X. (ed.): Valoración de Francisco Umbral. Ensayos críticos en torno a su obra, Gijón, Llibros del Pexe, 2003, pp. 187-205. UMBRAL, Francisco: «La noche que llegué al Café Gijón», en Hojas de Madrid, Barcelona, Planeta, 2008, pp. 625-805.

-----: Teoría de Lola y otros cuentos, Barcelona, Destino, 1977. 